\title{
Effect of low-frequency electric field screening on motility of human sperm
}

\author{
Romuald Górski ${ }^{1, A, C-F} \oplus$, Małgorzata Kotwickaa ${ }^{2, A, C, E-F}{ }^{\oplus}$, Izabela Skibińska ${ }^{2, A-B, D \oplus}$, \\ Magdalena Jendraszak ${ }^{2, A-B, E \oplus}$, Stanisław Wosiński, ${ }^{3, A, E \oplus ~}$ \\ ${ }^{1}$ University of Life Sciences, Poznan, Poland \\ 2 University of Medical Sciences, Poznan, Poland \\ ${ }^{3}$ ADR Technology, Gdansk, Poland \\ A - Research concept and design, B - Collection and/or assembly of data, C - Data analysis and interpretation, \\ $D$ - Writing the article, $E$ - Critical revision of the article, $F$ - Final approval of article
}

Górski R, Kotwicka M, Skibińska I, Jendraszak M, Wosiński S. Effect of low-frequency electric field screening on motility of human sperm. Ann Agric Environ Med. 2020; 27(3): 427-434. doi: 10.26444/aaem/116019

\begin{abstract}
Introduction. The human body is constantly exposed to an extremely low electromagnetic field (ELF-EMF), in particular at $50 \mathrm{~Hz}$, emitted by power lines, domestic distribution lines, electrical appliances, etc. It is assumed that the increase in electromagnetic exposure may cause adverse effects upon human health, as well as raising concerns regarding the impact on human fertility.

Objective. The aim of this in vitro study was to investigate the influence of ELF-EMF with a frequency of $50 \mathrm{~Hz}$ on the motility of human sperm. At the same time, the effectiveness of the dielectric screen constructed by ADR Technology in absorbing the emitted radiation was examined.

Materials and method. Semen samples of 20 patients were exposed to the influence of an extremely low electromagnetic field. After 5, 15 and 30 min., spermatozoa motility was analysed using a computer-assisted spermatozoa motility analysis system. The following sperm motility parameters were examined: 1 ) velocity straight linear motility; 2 ) cross-beat frequency; 3) lateral head displacement; 4) homogeneity of progressive motility velocity.

Results. It was found that the ELF-EMF presented a negative effect on the motility of human spermatozoa. A significant decrease in spermatozoa motility speed and a significant increase in lateral head deviation values were observed under the influence of the electromagnetic field. ELF-EMF did not show an effect on either lateral head displacement or homogeneity of progressive motility velocity.

Conclusions. A positive effect of the dielectric screen ADR Technology ${ }^{\circledR}$ was found. This effect compensated spermatozoa motility changes induced with ELF-EMF
\end{abstract}

\section{Key words}

human spermatozoa; male infertility; $50 \mathrm{~Hz}$ EMF - $50 \mathrm{~Hz}$ electromagnetic field; dielectric screen, ADR Technology ${ }^{\circledR}$

\section{INTRODUCTION}

Electrical currents exist naturally in the human body as an essential part of its daily functioning. Electrical processes are involved in both transmitting nerve signals and biochemical reactions related to digestion and brain activity, among others.

The spectrum of electromagnetic fields (EMF) in the environment is wide, but it can be classified depending on the wavelength range into extremely low frequency (ELF), radiofrequency field (RF), and microwave radiation, including frequencies from $3 \mathrm{~Hz}-300 \mathrm{GHz}$. The flow of the electric current is accompanied by the presence of electric and magnetic fields in the proximity of such appliances as electrical cables, radars, and satellite or wireless networks. Everyday use of electrical household equipment, such as microwave ovens, industrial heating, garage door openers, and the rapid development of technologies, i.e. the internet, cellular phone networks, laptop and satellite navigation systems, has resulted in an ever-increasing electromagnetic 'smog', which is hazardous to human health.

Address for correspondence: Małgorzata Kotwicka, Poznan University of Medical Sciences, Poland

E-mail: mkotwic@ump.edu.pl

Received: 29.09.2019; accepted: 31.12.2019; first published: 27.01.2020
Exposure to electromagnetic fields may cause adverse biological effects on the functioning of living organisms, e.g. induce oxidative stress and apoptosis, affect neural functions in the human brain, or functioning of the reproductive system [1-3]. It should also be noted that long-term exposure to an electromagnetic field, even if of low strength, may influence people's well-being [4-12]. Animal studies have proved that electromagnetic fields might present genotoxic effects and lead to significantly increased DNA damage in rats after exposure to a $60 \mathrm{~Hz}, 10 \mu \mathrm{T}$ magnetic fields for 24 or 48 hours [13]. In humans, it has also been reported that $50 \mathrm{~Hz}$ EMF elevates the frequencies of sister chromatid exchanges in lymphocytes [14]. Interestingly, DNA damage in human cells exposed to ELF-EMFs was counteracted by the addition of antioxidants, suggesting that ELF can indirectly affect DNA integrity, possibly via changes in radical homeostasis [15].

In 2002, the International Agency for Research on Cancer (IARC) published a monograph on the evaluation of carcinogenic risks of static and extremely low frequency electric and magnetic fields to humans [16]. Epidemiological studies have shown a correlation with an increased leukemia risk for children exposed to ELF, as well as increased risk of breast and brain cancer [17-19]. ELF-EMFs can also promote the development of cancer through non-genotoxic mechanisms, such as stimulation of cell proliferation 
and inhibition of apoptosis. Moreover, an increase in cell proliferation markers in rat mammary glands has been reported, as well as inhibition of UV radiation-induced apoptosis in mouse skin [20,21].

The effect of different levels of EMF emitted by devices such as mobile phones, laptop computers, microwave ovens or Wi-Fi on male fertility has been also reported [22-27]. Male infertility has become a common public health problem and is assumed to be caused by several factors that prevent the delivery of sperm to the fertilization site, such as poor semen parameters, spermatogenesis disturbance, and various dysfunctions of the male reproductive tract. Apart from well-determined factors causing male infertility (hormonal problems, chronic diseases, injuries, and lifestyle choices), there is a wide range of unknown factors, contributing to idiopathic male infertility. Even though the influence of several environmental factors, including chemical and physical exposures at home/work or during leisure, on decreasing semen parameters and male fertility is indisputable, it is difficult to estimate their real contribution to the infertility problem $[23,28-31]$.

The influence of EMFs on human tissues depends on the value of the specific absorption rate (SAR) which relies on the duration of exposure to radiation, its intensity, polarization and frequency $[32,33]$. A higher SAR may be associated with keeping the device in a trouser pocket, using a laptop connected to $\mathrm{Wi}-\mathrm{Fi}$, and keeping the phone close to the head while talking. It should be considered that Wi-Fi-equipped personal computers and mobile phones are typically positioned near reproductive organs [34]. As functions of the male reproductive system depend on cross-talk among the hypothalamus, pituitary gland and testis, the processes within these tissues may be differently affected by EMFs, depending on the SAR absorbed.

Semen quality, which is considered one of the key factors influencing reproductive success, may decrease after exposure to various common sources of EMF (laptop computers, mobile phones, and many wireless Internet-connected devices) $[24,35,36]$. It is suggested that sperm parameters such as motility, morphology, viability, sperm count and concentration, can be adversely affected and decreased by the use of mobile phones $[32,33,35,37,38]$. Several studies suggest that the rapid progressive motility of spermatozoa may be decreased by carrying mobile phones in the trouser pocket $[39,40]$. However, Wdowiak et al., indicate that time and the course of capacitation can be positively influenced by particular frequencies of electromagnetic radiation, and that the exposure to $43-\mathrm{kHz}$ electromagnetic waves increased the percentage of sperm cells displaying progressive motility [41]. Not only EMF affect sperm parameters, but also may cause hormonal changes in testis, and decrease the number of spermatogenic cells by triggering apoptosis and alter the fertilization rates $[42,43]$. Moreover, an increase in DNA damage may be observed as a consequence of increased oxidative stress induced by RF-EMF exposure [44-46]. This may subsequently lead to increased testicular carcinogenesis, as well as to the accelerated death of sperm cells [47]. It is also suggested that EMF exposure may affect the kinases' activity in the sperm cell cycle, leading to apoptosis, microtubule and mitochondrial function, which are crucial in the motility of sperm cells, as well as cause chromosomal and micronuclei damages and genomic instability $[38,48,49]$. In the light of the above threats, it seems necessary for future research to seek safety criteria in the influence of EMFs on the male reproductive system.

As various devices emitting non-ionizing radiation are very often carried close to the body, it seems that the ideal solution would be to create a screen matched with the characteristics to suppress the harmful fields of radiation. Attenuation of radio frequencies by conventional screens in homes or offices that are not exposed to excessive levels (such as in the proximity to broadcasting stations) is undesirable. It causes an unnecessary increase in the mobile phone's transmitted power, interference with radio signal reception from mobile receivers, or the blocking of Internet wireless connectivity. Furthermore, the naturally occurring electric field is part of the environment, and its removal with a Faraday cage has an adverse effect on health, as shown in animal studies [50].

Studies regarding the effects of exposure of the reproductive system to EMFs have provided conflicting results, ie. on morphology and function of the reproductive organs, hormonal profile, and biology of sperm cells [41, 51-53].

\section{OBJECTIVES}

The study was designed to investigate the influence of ELFEMF on the motility of human spermatozoa using different characteristics of applied ELF-EMF. Also, the effectiveness of the dielectric screen in absorbing the emitted radiation was examined. Another aim was to establish whether the shielding applied to the electronic devices using radiation frequencies commonly applied in the devices, such as mobile phones or laptop computers, could block EMFs and, as a consequence, improve semen parameters.

\section{MATERIALS AND METHOD}

The experiment employed fresh semen samples from 20 men aged $24-45$, diagnosed at the Department of Infertility and Endocrinology of Reproduction at Poznan University of Medical Sciences. The semen was obtained by masturbation after 2-5 days of sexual abstinence. A routine andrological analysis was carried out to evaluate standard semen parameters, such as volume, $\mathrm{pH}$, viscosity, concentration, motility, and morphology. Material meeting the conditions of normozospermia according to WHO 2010 was selected for the study:

- concentration: $15 \mathrm{million} / \mathrm{ml}\left(\geq 15 \times 10^{6} / \mathrm{ml}\right)$;

- percentage of live spermatozoa $(\geq 58 \%)$;

- $\geq$ sperm cells showing progressive motility (32\%);

- $\geq 4 \%$ sperm of normal morphology with leukocytes content $\left(<1 \times 10^{6} / \mathrm{ml}\right)[54]$.

Assessment of sperm cells motility. Motility was analyzed in human sperm $\left(1 \times 10^{5}\right.$ sperm cells $\left./ \mathrm{ml}\right)$ suspended in Hams F-10 medium using a computer-assisted spermatozoa motility analysis system. $10 \mu \mathrm{l}$ of spermatozoa suspension was spotted onto a Cell Vision chamber slide, producing a specimen with homogeneous thickness. Images were collected at a frequency of 60 frames per second using a Pixel-Link camera. Motility in the microscopic specimen was assessed in a minimum of 10 different fields for each case, yielding a minimum of 700 analyzed sperm cells. Acquisition time - 
2.08 s; analysed area $-640 \times 470 \mu \mathrm{m}$; resolving power -0.86 points. All measurements were performed at a constant, controlled temperature of $24^{\circ} \mathrm{C}$. The following sperm motility parameters were analysed:

1) velocity straight linear motility (VSLM);

2) cross-beat frequency (CBF);

3) lateral head displacement (LHD); 4) homogeneity of progressive motility velocity (HPMV) (Fig. 1).

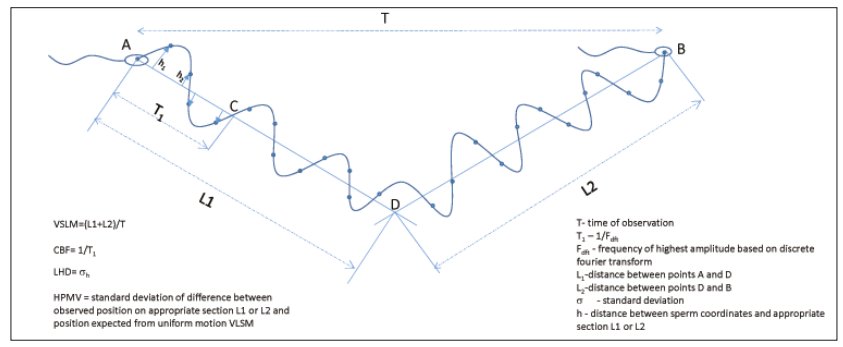

Figure 1. Different sperm motility parameters measured using a computer-assisted spermatozoa motility analysis system

These parameters were calculated as follows:

1) VSLM was calculated by matching the sperm path with two sectors (the method involves $n$ sectors where $n-1$ is the period of observation in seconds). The sectors were obtained, minimizing total sum, evaluated for all sectors, of squared distances from the sector to sperm mass centre. The idea was to avoid the erratic evaluation of VSL for colliding sperms, often found in higher sperm concentrations.

2) CBF was evaluated using Fourier series calculated by distances from sperm mass centre to corresponding sectors (see VSL calculation).

3) LHD was calculated as the standard deviation of distances from the sperm mass centre to corresponding sectors (see VSLM calculation).

4) HPMV was evaluated as the standard deviation of distances from predicted sperms orthogonal cast on corresponding (see VSLM calculation) and sperm mass centre cast. This parameter describes the vibration of sperm observed regarding velocity (VSLM) along the sperm pathway.

Exposure of sperm cells to EMFs. Commonly used electric field shields are based on conductive media which need electric grounding: metal foil, polymer or glass-housed metal meshes, conducting polymers, cotton/polyester blended with micro-fine silver or stainless steel fibres. A co-author of this paper has designed an advanced technology based on a nanocomposite in which the electric component of the electromagnetic radiation is absorbed by water dispersed in various ways in a dielectric matrix (Fig. 2) [55,56]. As the frequencies of the dielectric absorption bands of water are determined by its state of aggregation, an ice-like behaviour of water has been engineered by nanopore confinement.

The advanced dielectric composite consists of a polymer or ceramic matrix in which water is randomly dispersed in various ways. The composite exhibits high dielectric absorption in the low frequency range and does not need grounding. The shielding ability of the composite can be tailored to various applications by selecting an appropriate microstructure for the dielectric matrix (varying the pore sizes by processing conditions, or choosing characteristic properties) and by loading with aqueous solutions of

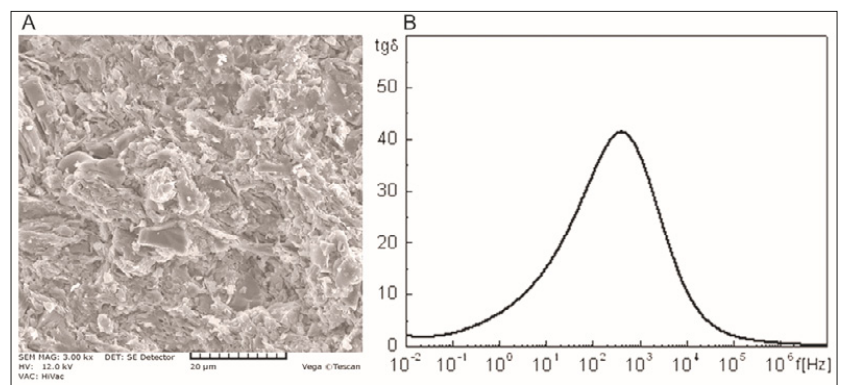

Figure 2. A) Scanning electron microscopy image of a fracture of a ceramic matrix $\left.\left(\mathrm{p}-20 \mathrm{MPa}, \mathrm{T}_{\mathrm{c}}=1100^{\circ} \mathrm{C}\right) ; \mathrm{B}\right)$ Frequency dependence of dielectric absorption of the composite shield at $16^{\circ} \mathrm{C}$ and relative humidity of $60 \%$

various hydrated salts and modifiers. The composites exhibit high dielectric absorption and shields electric fields within the frequency range from $\sim 100 \mathrm{mHz}-\sim 100 \mathrm{kHz}$. The electric field strength can be decreased by about two orders of magnitude, and the harmful effects of the electric component of electromagnetic fields on the human body can be considerably decreased.

Figure 2A shows an example of the topography of a ceramic matrix. The frequency dependence of dielectric absorption of the matrix impregnated with the aqueous solution containing $\mathrm{MgCl}_{2}$ and modifiers is resented in Figure 2B.

Tested semen samples were subjected to electromagnetic fields emitted by a specially designed device (EM emitter) (Fig. 3). The device emitting electromagnetic fields is composed of four spiral coils, constructed using a glassepoxy laminate coated with copper $(20 \mu \mathrm{m})$ which is used for printed circuits. The coils are placed directly behind the upper wall of the housing which is made of plastic and connected by electrical wires. The electrical wires are separated from the coils at a distance of about $5 \mathrm{~cm}$. The distance between the coils is $15 \mathrm{~cm}$. The electricity receiver is a $57 \mathrm{~W}$ halogen bulb placed in a lamp outside the casing of the device, at a distance of a few meters to minimize the influence of thermal radiation of the bulb on the tested object. A black shade on the lamp prevented light exiting to the outside and its possible influence on the experiment's objects. Four sectors were separated on the device. Thus different types of electromagnetic fields were produced. They were marked:

"E" - a sector emitting electromagnetic radiation with the predominance of the electrical component;

"EM" - a field emitting electromagnetic radiation without domination of its components;

"EM+ DS" (DS -Dielectric Screening) - an electromagnetic field shielded with a dielectric, reducing the intensity of its electrical component;

"M" - a field with a predominance of magnetic component.

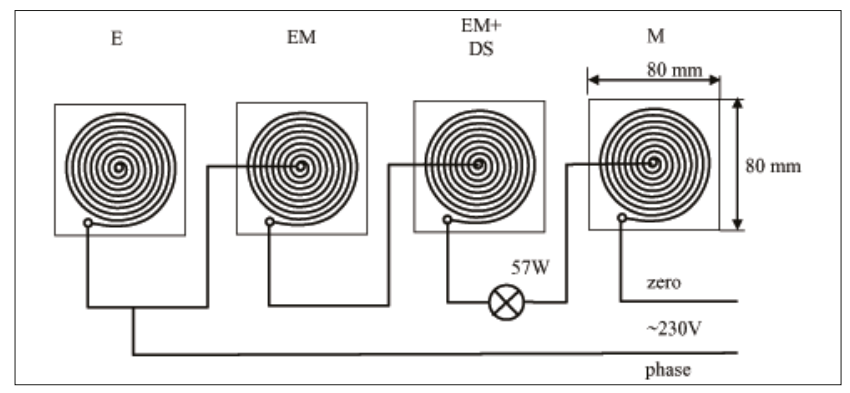

Figure 3. Schematic diagram of equipment used in the application of EMF 
The screen absorbing electromagnetic radiation, more precisely its electrical component, consited of four layers of dielectric material which was applied from the upper side of the wall of the device housing, in the place marked as EM+ DS. When the bulb is lit, between the bulb and zero (neutral) there is a predominance of magnetic field $(M)$, between the lit bulb and the phase (live) there is an electric and magnetic field, where the antenna is connected only to the phase (live) when there is a predominance of electric field (E) (Fig. 3).

Samples with human semen were placed individually in the mentioned sectors, emitting differential electromagnetic fields. Specific values of the field components generated by the device are shown in Table 1.

Table. 1. Values of intensity of electromagnetic fields were measured at a distance of $9 \mathrm{~mm}$ between the field generating device and the measuring probe; this was a practical minimum in order to insert the dielectric material without contact with the device or probe. Measurements were performed using the Maschek E-100. The field generating system was loaded with a $57 \mathrm{~W}$ receiver

\begin{tabular}{ccccc} 
& M & EM & EM+ DS & E \\
\hline$E$ & $329 \mathrm{~V} / \mathrm{m}$ & $1640 \mathrm{~V} / \mathrm{m}$ & $196 \mathrm{~V} / \mathrm{m}$ & $1887 \mathrm{~V} / \mathrm{m}$ \\
\hline$M$ & $7.2 \mu \mathrm{T}$ & $7.17 \mu \mathrm{T}$ & $6.21 \mu \mathrm{T}$ & $0.29 \mu \mathrm{T}$
\end{tabular}

$E$-an electrical component; $M$ - a magnetic component; $E$ - an electromagnetic field with the predominance of the electrical component; $M$ - an electromagnetic field with the predominance of the magnetic component; EM -an electromagnetic field without any domination of its components; EM+ DS - an electromagnetic field with Dielectric Screening (DS)

Statistical analysis. Statistical analysis was performed using Statistica v. 13 software (TIBCO Software, Tulusa, USA). The distribution of parameters was assessed with the Shapiro-Wilk test, and the mean values compared using the Kruskal-Wallis test with the Dunn post hoc test. Data was presented as mean \pm standard deviation. $\mathrm{P}<0.05$ was considered statistically significant.

\section{RESULTS}

Velocity straight linear motility (VSLM). Changes in the VSLM parameter values due to the stimulation of cells with E, $\mathrm{M}, \mathrm{EM}$, and $\mathrm{EM}+\mathrm{DS}$ after 5, 15 and 30 minutes are presented in Table 2.

After 5 minutes of exposure, a decrease in the mean VSLM value was recorded for all electromagnetic fields studied $(\mathrm{p}=0.03)$. However, this decrease was not statistically significant with reference to the control ( $p>0.05)$.

After 15 minutes, in combination with the application of an electromagnetic field without domination of its components (marked as EM), a significant reduction of the mean VSLM value was noted with reference to the control $(21.5 \pm 0.6 \mu \mathrm{m} / \mathrm{s}$ vs. $16.4 \pm 2.3 \mu \mathrm{m} / \mathrm{s} ; \mathrm{p}=0.02$ ). Subjecting sperm to the remaining tested electromagnetic fields did not result in statistically significant changes in VSLM values, compared to the control.

30 minutes exposure of spermatozoa to various combinations of electromagnetic fields (marked as E, M, EM) caused a significant decrease in the value of the VSLM parameter, which was particularly evident after using the electromagnetic field without dominating its components $(p=0.02)$.

It should be noted that screening this field by using a dielectric (EM+DS) effectively protected against lowering the spermatozoa progressive motility (VSLM). An analysis of variance showed that the mean VSLM value of sperm after 30 minutes of exposure of the shielded electromagnetic
Table 2. Evaluation of changes in velocity straight linear motility (VSLM) parameter of human sperm after electromagnetic field exposure $(\mathrm{N}=20)$

\begin{tabular}{|c|c|c|c|c|}
\hline & Mean & $\begin{array}{c}\text { Minimum } \\
{[\mu \mathrm{m} / \mathrm{s}]}\end{array}$ & Maximum & $\begin{array}{l}\text { Standard } \\
\text { deviation }\end{array}$ \\
\hline \multicolumn{5}{|c|}{ after 5 minutes } \\
\hline control & 20.4 & 15.5 & 22.9 & 3.1 \\
\hline$E$ & 17.7 & 15.4 & 19.9 & 2.6 \\
\hline M & 15.3 & 12.6 & 20.8 & 3.6 \\
\hline EM & 18.5 & 15.9 & 19.9 & 2.0 \\
\hline $\mathrm{EM}+\mathrm{DS}$ & 18.2 & 15.6 & 19.6 & 1.9 \\
\hline \multicolumn{5}{|c|}{ after 15 minutes } \\
\hline control & 21.6 & 21.1 & 22.2 & 0.6 \\
\hline$E$ & 22.8 & 18.4 & 29.4 & 4.6 \\
\hline M & 19.2 & 15.1 & 22.6 & 3.4 \\
\hline EM & 16.4 & 14.9 & 19.4 & 2.3 \\
\hline$E M+D S$ & 20.2 & 15.4 & 22.1 & 2.6 \\
\hline \multicolumn{5}{|c|}{ after 30 minutes } \\
\hline control & 22.6 & 22.2 & 22.9 & 0.4 \\
\hline $\mathrm{E}$ & 17.9 & 14.8 & 22.1 & 3.8 \\
\hline M & 18.1 & 14.4 & 21.4 & 3.2 \\
\hline EM & 16.7 & 13.9 & 19.2 & 2.3 \\
\hline $\mathrm{EM}+\mathrm{DS}$ & 21.4 & 14.9 & 25.4 & 3.8 \\
\hline
\end{tabular}

$\mathrm{E}$ - an electromagnetic field with the predominance of the electrical component; $\mathrm{M}$ - an electromagnetic field with the predominance of the magnetic component: $E M$ - an electromagnetic field without the domination of its components; EM+DS - an electromagnetic field with Dielectric Screening (DS)

field did not differ significantly, compared to the control $(22.6 \pm 0.4 \mu \mathrm{m} / \mathrm{s} v s .21 .4 \pm 3.8 \mu \mathrm{m} / \mathrm{s} ; \mathrm{p}>0.05)$. It was evaluated that the mean VSLM value of sperm cells exposed to the electromagnetic field without the domination of either electrical or magnetic component was significantly lower in comparison to spermatozoa exposed to an electromagnetic field with dielectric screening $(16.7 \pm 0.4 \mu \mathrm{m} / \mathrm{s} v s .21 .4 \pm 3.8 \mu \mathrm{m} / \mathrm{s}$; $\mathrm{p}=0.03)$.

Cross-beat frequency (CBF). Changes in mean CBF values after 5, 15 and 30 minutes of stimulation E, M, EM, and $\mathrm{EM}+\mathrm{DS}$ are presented in Table 3. After 5 minutes, no significant differences in mean values of cross-beat frequency were found in all the examined combinations. No significant differences between the tested combinations for the CBF parameter were noted after 15 minutes.

A statistically significant $(\mathrm{p}<0.001)$ increase of CBF occurred after a 30 minute exposure to the electromagnetic field without domination of its components compared to the control $(7.9 \pm 0.6 \mathrm{~Hz} v s .5 .8 \pm 0.1 \mathrm{~Hz}$; $\mathrm{p}<0.001)$, and compared to the EMF with the predominance of the electrical component $(7.9 \pm 0.6 \mathrm{~Hz} v s .5 .4 \pm 0.9 \mathrm{~Hz} ; \mathrm{p}<0.001)$. No significant differences of the mean CBF values were observed between the control and electromagnetic field with dielectric screening (EM+DS) (5.85 $\pm 0.1 \mathrm{~Hz}$ vs. $5.4 \pm 0.9 \mathrm{~Hz} ; \mathrm{p}>005)$.

Lateral head displacement (LDH) and homogeneity of progressive motility velocity (HPMV). The conducted studies did not show the influence of the examined electromagnetic fields, regardless of the time of their exposure, on the spermatozoa motility parameters, such as lateral head displacement (LDH) and homogeneity of progressive motility velocity (HPMV) (Tab. 4, Tab. 5; p>0.05). 
Table 3. Evaluation of changes in cross-beat frequency (CBF) parameter of human sperm after electromagnetic field exposure $(\mathrm{N}=20)$

\begin{tabular}{lcccc}
\hline & Mean & $\begin{array}{c}\text { Minimum } \\
{[\mathrm{Hz}]}\end{array}$ & Maximum & $\begin{array}{c}\text { Standard } \\
\text { deviation }\end{array}$ \\
\hline after 5 minutes & & & & \\
\hline control & 5.7 & 4.6 & 6.8 & 0.9 \\
\hline E & 5.6 & 5.3 & 6.0 & 0.4 \\
\hline M & 6.1 & 5.2 & 7.1 & 0.9 \\
\hline EM & 6.2 & 5.1 & 8.0 & 1.4 \\
\hline EM+DS & 6.5 & 5.9 & 7.2 & 0.5 \\
\hline after 15 minutes & & & & \\
\hline control & 5.2 & 4.6 & 5.9 & 0.8 \\
\hline E & 4.9 & 3.9 & 6.2 & 1.1 \\
\hline M & 5.6 & 4.8 & 7.0 & 1.1 \\
\hline EM & 5.3 & 4.0 & 7.3 & 1.5 \\
\hline EM+DS & 5.7 & 5.3 & 6.3 & 0.4 \\
\hline
\end{tabular}

\section{after 30 minutes}

\begin{tabular}{lllll}
\hline control & 5.8 & 5.7 & 5.9 & 0.1 \\
\hline $\mathrm{E}$ & 5.3 & 3.5 & 7.1 & 1.7 \\
\hline $\mathrm{M}$ & 4.8 & 3.6 & 6.5 & 1.3 \\
\hline $\mathrm{EM}$ & 7.9 & 7.1 & 8.5 & 0.6 \\
\hline EM+DS & 5.4 & 4.3 & 6.3 & 0.9 \\
\hline
\end{tabular}

$E$ - an electromagnetic field with the predominance of the electrical component; $M$ - an electromagnetic field with the predominance of the magnetic component; EM - an electromagnetic field without thedomination ofitscomponents; EM+DS-anelectromagnet field with Dielectric Screening (DS)

Table 4. Evaluation of changes in lateral head displacement (LHD) of human sperm after electromagnetic field exposure $(\mathrm{N}=20)$

\begin{tabular}{|c|c|c|c|c|}
\hline & Mean & $\begin{array}{c}\text { Minimum } \\
{[\mu \mathrm{m}]}\end{array}$ & Maximum & $\begin{array}{l}\text { Standard } \\
\text { deviation }\end{array}$ \\
\hline \multicolumn{5}{|c|}{ after 5 minutes } \\
\hline control & 0.9 & 0.2 & 3.6 & 0.6 \\
\hline$E$ & 1.3 & 0.3 & 5.2 & 0.7 \\
\hline M & 0.9 & 0.3 & 3.8 & 0.7 \\
\hline EM & 1.0 & 0.2 & 4.6 & 0.7 \\
\hline $\mathrm{EM}+\mathrm{DS}$ & 0.9 & 0.2 & 3.8 & 0.8 \\
\hline \multicolumn{5}{|c|}{ after 15 minutes } \\
\hline control & 1.1 & 0.3 & 3.7 & 0.7 \\
\hline $\mathrm{E}$ & 1.1 & 0.2 & 6.4 & 0.7 \\
\hline M & 1.0 & 0.3 & 7.2 & 0.9 \\
\hline EM & 0.8 & 0.2 & 6.8 & 0.6 \\
\hline $\mathrm{EM}+\mathrm{DS}$ & 1.2 & 0.2 & 4.0 & 0.8 \\
\hline \multicolumn{5}{|c|}{ after 30 minutes } \\
\hline control & 1.0 & 0.2 & 6.4 & 0.7 \\
\hline$E$ & 0.9 & 0.2 & 3.5 & 0.6 \\
\hline M & 1.1 & 0.3 & 7.5 & 1.1 \\
\hline EM & 0.9 & 0.2 & 6.3 & 0.9 \\
\hline $\mathrm{EM}+\mathrm{DS}$ & 1.2 & 0.3 & 5.6 & 0.7 \\
\hline
\end{tabular}

$\mathrm{E}$ - an electromagnetic field with the predominance of the electrical component; $M$ - an electromagnetic field with the predominance of the magnetic component; EM - an electromagnetic field without any domination of its components; EM+DS - an electromagnetic field with Dielectric Screening (DS)
Table 5. Evaluation of changes in homogeneity of progressive motility velocity (HPMV) of human sperm after electromagnetic field exposure $(\mathrm{N}=20)$

\begin{tabular}{|c|c|c|c|c|}
\hline & Mean & $\begin{array}{c}\text { Minimum } \\
{[\mu \mathrm{m}]}\end{array}$ & Maximum & $\begin{array}{l}\text { Standard } \\
\text { deviation }\end{array}$ \\
\hline \multicolumn{5}{|c|}{ after 5 minutes } \\
\hline control & 1.7 & 0.3 & 8.5 & 1.2 \\
\hline $\mathrm{E}$ & 1.7 & 0.3 & 11.0 & 1.2 \\
\hline$M$ & 1.9 & 0.5 & 10.9 & 1.3 \\
\hline EM & 2.1 & 0.3 & 11.3 & 1.3 \\
\hline $\mathrm{EM}+\mathrm{DS}$ & 1.9 & 0.4 & 9.5 & 1.1 \\
\hline \multicolumn{5}{|c|}{ after 15 minutes } \\
\hline control & 2.0 & 0.5 & 10.9 & 1.2 \\
\hline $\mathrm{E}$ & 1.8 & 0.4 & 8.7 & 1.4 \\
\hline M & 2.1 & 0.3 & 13.3 & 1.4 \\
\hline EM & 1.8 & 0.4 & 11.4 & 1.3 \\
\hline EM+DS & 1.7 & 0.3 & 10.5 & 1.1 \\
\hline \multicolumn{5}{|c|}{ after 30 minutes } \\
\hline control & 2.2 & 0.5 & 11.4 & 1.5 \\
\hline $\mathrm{E}$ & 1.9 & 0.3 & 8.7 & 1.2 \\
\hline$M$ & 2.1 & 0.5 & 16.1 & 1.6 \\
\hline EM & 2.0 & 0.4 & 12.2 & 1.5 \\
\hline $\mathrm{EM}+\mathrm{DS}$ & 1.8 & 0.4 & 7.8 & 1.0 \\
\hline
\end{tabular}

$\mathrm{E}$ - an electromagnetic field with the predominance of the electrical component; $M$ - an electromagnetic field with the predominance of the magnetic component; EM - an electromagnetic field without the domination of its components; EM+DS - an electromagnetic field with Dielectric Screening (DS)

\section{DISCUSSION}

The structure of the device (EM electromagnetic field emitter) for irradiation of the studied male semen samples was based on the thesis that not only the variable magnetic field negatively affects living organisms, but that the variable electric also acts to a similar extent $[57,58]$.

In the conducted studies, a positive effect was found of the dielectric screen created in accordance with ADR Technology ${ }^{\oplus}$ (EM + Dielectric Screening), i.e., the dielectric screening reduced the influence of EMF upon the sperm tested. It almost completely compensated for the highly significant decrease in the speed of sperm motility (VSLM), and a clearly significant increase in lateral head deviation $(\mathrm{CBF})$ values due to the field emitter effecting the electromagnetic field without the domination of its components (EM combination). The effectiveness of the screen used is due to high dielectric absorption. Within the area where the semen samples were placed, the reduction of the harmful electric field after applying the dielectric screen was $88 \%$. It should be noted that the intensity of the magnetic field was maintained at the level generated by the EM emitter, as the dielectric material used in the tests shields the electric field by absorption, and not the magnetic field. Such a division exists for short-range fields.

In the conducted studies, a significant decrease in the value of the VSLM parameter was also observed after a 30-minute exposure of the semen to the electromagnetic field with the dominant electrical component (combination E) or with the dominant magnetic component (combination M). However, this decrease was less than that observed for the electromagnetic field in which the values of the 
individual components are at their maximum values (EM combination). In the case of lateral head deviation (CBF), both the electromagnetic field with the dominant electrical and magnetic components did not cause significant changes compared to the control. However, significant increases in the CBF parameter occurred, as for the lateral head deviation (VSLM, when an electromagnetic field was applied without the domination of its components (EM). When the electromagnetic field was shielded due to absorption in the dielectric screen, the value of the VSLM and CBF parameters were not statistically significant, i.e., they became similar to the control, even though the magnetic field passed through the screen almost without loss.

Interestingly, the exceptionally rapid, significant physiological reaction of spermatozoa to the applied electromagnetic fields was observed only after 30 minutes. However there are studies that indicate changes only after a few hours of interaction of electromagnetic field emitters, after at least 1 hour [44,59-62].

Studies performed on mammalian sperm cells have shown that ELF-EMF can have either a positive or negative effect on sperm motility. This depends on the characteristics of the applied EMF and/or on the type of sperm used [63-65]. In the research carried out by Bernabo et al. [63] it was found that after $1 \mathrm{~h}$ of exposure of boar spermatozoa to ELF, reduced motility was observed. A modest reactivity was established when cells were co-incubated with solubilized zonae pellucidae and a reduction in oocyte penetrating ability was also observed. Moreover, after 2 or $4 \mathrm{~h}$ of incubation, the signs of morphological damage appeared on the plasma membrane and at the acrosomal level. The results of these studies suggest that a long term exposure to ELF might have adverse effects on mammalian fertility and reproduction. Hong et al. [66] reported that $50 \mathrm{~Hz}$ EMFs $(0.2 \mathrm{mT}$ or $6.4 \mathrm{mT}$, exposed for 4 weeks) may have the potential to induce DNA strand breakage in testicular cells and can affect sperm chromatin condensation in mice. In other studies carried out on mice, Kim et al. [43] examined the effect of a 16-month continuous exposure to $60 \mathrm{~Hz}$ and $14 \mu \mathrm{T}$ electromagnetic field on the apoptosis of testicular cells. The results indicate that apoptosis may be induced in spermatogenic cells by continuous exposure to ELF-EMF.

Al-Akhras et al. [67] treated male adult rats to ELF-EMF ( $50 \mathrm{~Hz}$ and $25 \mu \mathrm{T}$ ) for 18 weeks. The authors observed a significant reduction in the weight of the seminal vesicles and preputial glands in the exposed male rats, along with significant reduction in sperm count. At the same time, a significant increase in the serum levels of male luteinizing hormone (LH) and a decrease in testosterone level after an 18-week exposure period was observed. Avendano et al. [24] reported that normozoospermic, exposed ex vivo for a 4-hour duration to a laptop connected to the Internet by Wi-Fi (ELF-EMF and Wi-Fi exposure), showed a significant decrease in human sperm motility and an increase in DNA fragmentation. These results indicate that keeping wireless Internet connection near the testes may result in decreased male fertility. However, Sun et al. [68] investigated the effects of ELF emitted by computers on human spermatozoa quality and did not find any adverse effect.

In contrast to the presented study, in which the negative effect of electromagnetic fields on the mobility of human spermatozoa was found, the studies conducted by Iorio et al. reported that ELF-EMF with a frequency of $50 \mathrm{~Hz}$ and the waveform of $5 \mathrm{mT}$ amplitude caused an increase in kinematic parameters and motility of human sperm [64,65]. This explains the positive impact of EMF on sperm mitochondrial metabolism [increase of mitochondrial membrane potential and levels of ATP, ADP and NAD(+)].

Several studies indicate a harmful effect of higher frequency electromagnetic fields, i.e., RF-EMF, emitted by mobile phones and wireless Wi-Fi connections on the reproductive systems of mammals compared to ELF-EMF. For example, it was indicated that mobile phones stored close to male gonads negatively influence human sperm parameters, such as concentration and motility $[35,39,42]$. A study carried out by Wdowiak et al. on a population using mobile phones (GSM equipment), spread over a period of 1-2 years indicated that the sperm quality is lowered. The authors reported a decrease in the percentage of sperm cells with normal motility in the semen [69].

The decrease in motility correlates with the frequency of using mobile phones. Gutschi et al. studied human sperm obtained from 2,110 patients attending clinics from 1993 - 2007. The authors concluded that cell phone use had a negative effect on the sperm quality in men [70]. Falzone et al. exposed highly motile human spermatozoa to $900 \mathrm{MHz}$ for $1 \mathrm{~h}$. The authors showed that RF-EMF had a significant effect on sperm morphometry. They obtained a significant reduction in sperm head area, and also observed a significant decrease in sperm binding to the hemizona [71].

Otitoloju et al. exposed male mice to radiofrequency radiations at a mobile phone (GSM) base station. Sperm head abnormalities occurred in 39\%-46\% of exposed mice, but in only $2 \%$ of the controls [72]. De Iuliis et al. showed that motility and vitality of human spermatozoa were significantly reduced after RF radiation exposure, while the mitochondrial generation of reactive oxygen species and DNA fragmentation were significantly elevated [44]. Yan et al. studied the effects of mobile phone emissions on sperm motility in rats. Rats were exposed to two 3-hour periods of daily emissions for 18 weeks. The authors concluded that the exposed animals exhibited a significantly higher incidence of sperm cell death than the control [37]. In addition, abnormal clumping of sperm cells was present in rats exposed to mobile phone emissions. Gul et al. found that mobile phone microwaves exposure has toxic effects on ovarian follicles in female rats [73]. In studies conducted on mice, Aitken et al. observed no influence RF radiation exposure on sperm number, morphology and vitality [74]. However, a detailed analysis of DNA revealed significant damage to both the mitochondrial genome and the nuclear beta-globin locus. Studies show that $2.45 \mathrm{GHz}$ microwave exposure leads to both a decrease in testosterone and melatonin plasma levels and an increase in creatine kinase and caspase- 3 activity in the sperm cells of exposed rats [75]. Ex vivo studies regarding the influence of Wi-Fi radiation indicated its influence on testis structure and the sexual behavior of exposed rats $[76,77]$.

\section{CONCLUSIONS}

An extremely low electromagnetic field (ELF-EMF), in either electrical or magnetic component, revealed negative effect on human spermatozoa motility. The dielectric screen constructed by ADR Technology ${ }^{\circledast}$ effectively protected against spermatozoa motility decrease. 


\section{REFERENCES}

1. Kim JH, Lee J-K, Kim H-G, Kim K-B, Kim HR. Possible Effects of Radiofrequency Electromagnetic Field Exposure on Central Nerve System. Biomol Ther (Seoul). 2019; 27: 265-275. doi:10.4062/ biomolther.2018.152

2. Kivrak E, Yurt K, Kaplan A, Alkan I, Altun G. Effects of electromagnetic fields exposure on the antioxidant defense system. J Microsc Ultrastruct. 2017; 5: 167. doi:10.1016/j.jmau.2017.07.003

3. Wdowiak A, Mazurek PA, Wdowiak A, Bojar I. Effect of electromagnetic waves on human reproduction. Ann Agric Environ Med. 2017; 24: 13-18. doi:10.5604/12321966.1228394

4. World Health Organization (WHO). Establishing a dialogue on risks from electromagnetic fields. Geneva; 2002.

5. World Health Organization (WHO). Extremely low frequency fields. 2007.

6. Draper G, Vincent T, Kroll ME, Swanson J. Childhood cancer in relation to distance from high voltage power lines in England and Wales: a casecontrol study. BMJ. 2005; 330: 1290. doi:10.1136/bmj.330.7503.1290

7. Blackman CF. Can EMF Exposure During Development Leave an Imprint Later in Life? Electromagn Biol Med. 2006; 25: 217-225. doi:10.1080/15368370601034086

8. Hardell L, Sage C. Biological effects from electromagnetic field exposure and public exposure standards. Biomed Pharmacother. 2008; 62: 104 109. doi:10.1016/j.biopha.2007.12.004

9. Johansson O. Disturbance of the immune system by electromagnetic fields-A potentially underlying cause for cellular damage and tissue repair reduction which could lead to disease and impairment. Pathophysiology. 2009; 16: 157-177. doi:10.1016/j.pathophys.2009.03.004

10. Phillips JL, Singh NP, Lai H. Electromagnetic fields and DNA damage. Pathophysiology. 2009; 16: 79-88. doi:10.1016/j.pathophys.2008.11.005

11. Ruediger HW. Genotoxic effects of radiofrequency electromagnetic fields. Pathophysiology. 2009; 16: 89-102. doi:10.1016/j.pathophys.2008.11.004

12. Milham S. Historical evidence that electrification caused the 20th century epidemic of "diseases of civilization." Med Hypotheses. 2010; 74: 337-345. doi:10.1016/j.mehy.2009.08.032

13. Lai H, Singh NP. Magnetic-field-induced DNA strand breaks in brain cells of the rat. Environ Health Perspect. 2004; 112: 687. doi:10.1289/ EHP.6355

14. Wahab MA, Podd JV, Rapley BI, Rowland RE. Elevated sister chromatid exchange frequencies in dividing human peripheral blood lymphocytes exposed to $50 \mathrm{~Hz}$ magnetic fields. Bioelectromagnetics. 2007; 28: 281288. doi:10.1002/bem.20289

15. Wolf FI, Torsello A, Tedesco B, Fasanella S, Boninsegna A, D’Ascenzo $\mathrm{M}$, et al. 50-Hz extremely low frequency electromagnetic fields enhance cell proliferation and DNA damage: possible involvement of a redox mechanism. Biochim Biophys Acta - Mol Cell Res. 2005; 1743: 120-129. doi:10.1016/j.bbamcr.2004.09.005

16. IARC Working Group on the Evaluation of Carcinogenic Risks to Humans. Non-ionizing radiation, Part 1: static and extremely lowfrequency (ELF) electric and magnetic fields. IARC Monogr Eval Carcinog risks to humans. 2002; 80: 1-395.

17. Ahlbom A, Day N, Feychting M, Roman E, Skinner J, Dockerty J, et al. A pooled analysis of magnetic fields and childhood leukaemia. Br J Cancer. 2000; 83: 692-698. doi:10.1054/bjoc.2000.1376

18. Greenland S, Sheppard AR, Kaune WT, Poole C, Kelsh MA. A pooled analysis of magnetic fields, wire codes, and childhood leukemia. Childhood Leukemia-EMF Study Group. Epidemiology. 2000; 11: 624-634.

19. Foliart DE, Pollock BH, Mezei G, Iriye R, Silva JM, Ebi KL, et al. Magnetic field exposure and long-term survival among children with leukaemia. Br J Cancer. 2006; 94: 161-164. doi:10.1038/sj.bjc.6602916

20. Fedrowitz M, Westermann J, Löscher W. Magnetic field exposure increases cell proliferation but does not affect melatonin levels in the mammary gland of female Sprague Dawley rats. Cancer Res. 2002; 62: $1356-63$.

21. Kumlin T, Heikkinen P, Kosma V-M, Alhonen L, Jänne J, Juutilainen J. p53-independent apoptosis in UV-irradiated mouse skin: possible inhibition by $50 \mathrm{~Hz}$ magnetic fields. Radiat Environ Biophys. 2002; 41: $155-8$.

22. Viel J-F, Cardis E, Moissonnier M, de Seze R, Hours M. Radiofrequency exposure in the French general population: Band, time, location and activity variability. Environ Int. 2009; 35: 1150-1154. doi:10.1016/j. envint.2009.07.007

23. Li D-K, Yan B, Li Z, Gao E, Miao M, Gong D, et al. Exposure to magnetic fields and the risk of poor sperm quality. Reprod Toxicol. 2010; 29: 86-92. doi:10.1016/j.reprotox.2009.09.004
24. Avendaño C, Mata A, Sanchez Sarmiento CA, Doncel GF. Use of laptop computers connected to internet through Wi-Fi decreases human sperm motility and increases sperm DNA fragmentation. Fertil Steril. 2012; 97: 39-45.e2. doi:10.1016/j.fertnstert.2011.10.012

25. Kesari KK, Kumar S, Nirala J, Siddiqui MH, Behari J. Biophysical Evaluation of Radiofrequency Electromagnetic Field Effects on Male Reproductive Pattern. Cell Biochem Biophys. 2013; 65: 85-96. doi:10.1007/s12013-012-9414-6

26. Nazıroğlu M, Yüksel M, Köse SA, Özkaya MO. Recent Reports of Wi-Fi and Mobile Phone-Induced Radiation on Oxidative Stress and Reproductive Signaling Pathways in Females and Males. J Membr Biol. 2013; 246: 869-875. doi:10.1007/s00232-013-9597-9

27. McGill JJ, Agarwal A. The Impact of Cell Phone, Laptop Computer, and Microwave Oven Usage on Male Fertility. Male Infertility. New York, NY: Springer New York; 2014. pp. 161-177. doi:10.1007/978-14939-1040-3_11

28. Irvine S, Cawood E, Richardson D, MacDonald E, Aitken J. Evidence of deteriorating semen quality in the United Kingdom: birth cohort study in 577 men in Scotland over 11 years. BMJ. 1996; 312: 467-471. doi:10.1136/bmj.312.7029.467

29. Carlsen E, Swan SH, Petersen JH, Skakkebæk NE. Longitudinal changes in semen parameters in young Danish men from the Copenhagen area. Hum Reprod. 2005; 20: 942-949. doi:10.1093/humrep/deh704

30. Shokri S, Soltani A, Kazemi M, Sardari D, Mofrad FB. Effects of Wi-Fi $(2.45 \mathrm{GHz})$ Exposure on Apoptosis, Sperm Parameters and Testicular Histomorphometry in Rats: A Time Course Study. Cell J. 2015; 17: 322-31. doi:10.22074/CELLJ.2016.3740

31. Belyaev I, Dean A, Eger H, Hubmann G, Jandrisovits R, Kern M, et al. EUROPAEM EMF Guideline 2016 for the prevention, diagnosis and treatment of EMF-related health problems and illnesses. Rev Environ Health. 2016; 31: 363-97. doi:10.1515/reveh-2016-0011

32. Agarwal A, Singh A, Hamada A, Kesari K. Cell phones and male infertility: a review of recent innovations in technology and consequences. Int Braz J Urol. 2011; 37: 432-54. doi:10.1590/s167755382011000400002

33. Kesari KK, Agarwal A, Henkel R. Radiations and male fertility. Reprod Biol Endocrinol. 2018; 16: 118. doi:10.1186/s12958-018-0431-1

34. Santini SJ, Cordone V, Falone S, Mijit M, Tatone C, Amicarelli F, et al. Role of Mitochondria in the Oxidative Stress Induced by Electromagnetic Fields: Focus on Reproductive Systems. Oxid Med Cell Longev. 2018; 2018: 1-18. doi:10.1155/2018/5076271

35. Erogul O, Oztas E, Yildirim I, Kir T, Aydur E, Komesli G, et al. Effects of Electromagnetic Radiation from a Cellular Phone on Human Sperm Motility: An In Vitro Study. Arch Med Res. 2006; 37: 840-843. doi:10.1016/j.arcmed.2006.05.003

36. Agarwal A, Desai NR, Makker K, Varghese A, Mouradi R, Sabanegh E, et al. Effects of radiofrequency electromagnetic waves (RF-EMW) from cellular phones on human ejaculated semen: an in vitro pilot study. Fertil Steril. 2009; 92: 1318-1325. doi:10.1016/j.fertnstert.2008.08.022

37. Yan J-G, Agresti M, Bruce T, Yan YH, Granlund A, Matloub HS. Effects of cellular phone emissions on sperm motility in rats. Fertil Steril. 2007; 88: 957-964. doi:10.1016/j.fertnstert.2006.12.022

38. Kesari KK, Behari J. Evidence for mobile phone radiation exposure effects on reproductive pattern of male rats: Role of ROS. Electromagn Biol Med. 2012; 31: 213-222. doi:10.3109/15368378.2012.700292

39. Kilgallon SJ, Simmons LW. Image content influences men's semen quality. Biol Lett. 2005; 1: 253-5. doi:10.1098/rsbl.2005.0324

40. Al-Bayyari N. The effect of cell phone usage on semen quality and fertility among Jordanian males. Middle East Fertil Soc J. 2017; 22: 178-182. doi:10.1016/J.MEFS.2017.03.006

41. Wdowiak A, Mazurek P, Wdowiak A, Bojar I. Low frequency electromagnetic waves increase human sperm motility - A pilot study revealing the potent effect of $43 \mathrm{khz}$ radiation. Int J Occup Med Environ Health. 2018; 31: 723-739. doi:10.13075/ijomeh.1896.01262

42. Fejes I, Závaczki Z, Szöllősi J, Koloszár S, Daru J, Kovács L, et al. Is there a relationship between cell phone use and semen quality? Arch Androl. 2005; 51: 385-393. doi:10.1080/014850190924520

43. Kim Y-W, Kim H-S, Lee J-S, Kim Y-J, Lee S-K, Seo J-N, et al. Effects of $60 \mathrm{~Hz} 14 \mu \mathrm{T}$ magnetic field on the apoptosis of testicular germ cell in mice. Bioelectromagnetics. 2009; 30: 66-72. doi:10.1002/bem.20448

44. De Iuliis GN, Newey RJ, King B V, Aitken RJ. Mobile Phone Radiation Induces Reactive Oxygen Species Production and DNA Damage in Human Spermatozoa In Vitro. Zhang B, editor. PLoS One. 2009; 4: e6446. doi:10.1371/journal.pone.0006446

45. Kumar S, Nirala JP, Behari J, Paulraj R. Effect of electromagnetic irradiation produced by $3 \mathrm{G}$ mobile phone on male rat reproductive system in a simulated scenario. Indian J Exp Biol. 2014; 52: 890-7. 
46. Meena R, Kumari K, Kumar J, Rajamani P, Verma HN, Kesari KK. Therapeutic approaches of melatonin in microwave radiations-induced oxidative stress-mediated toxicity on male fertility pattern of Wistar rats. Electromagn Biol Med. 2014; 33: 81-91. doi:10.3109/15368378.2 013.781035

47. Desai N, Sharma R, Makker K, Sabanegh E, Agarwal A. Physiologic and pathologic levels of reactive oxygen species in neat semen of infertile men. Fertil Steril. 2009; 92: 1626-1631. doi:10.1016/j. fertnstert.2008.08.109

48. Kesari KK, Behari J. Effects of microwave at $2.45 \mathrm{GHz}$ radiations on reproductive system of male rats. Toxicol Environ Chem. 2010; 92: 1135-1147. doi:10.1080/02772240903233637

49. Luzhna L, Kathiria P, Kovalchuk O. Micronuclei in genotoxicity assessment: from genetics to epigenetics and beyond. Front Genet. 2013; 4: 131. doi:10.3389/fgene.2013.00131

50. Lang S. Stoffwechselphysiologische Auswirkungen der Faradayschen Abschirmung und eines künstlichen luftelektrischen Feldes der Frequenz $10 \mathrm{~Hz}$ auf weiße Mäuse. Arch für Meteorol Geophys und Bioklimatologie Ser B. 1972; 20: 109-122. doi:10.1007/BF02243318

51. Singh R, Nath R, Mathur AK, Sharma RS. Effect of radiofrequency radiation on reproductive health. Indian J Med Res. 2018; 148: S92-S99. doi:10.4103/ijmr.IJMR_1056_18

52. Ozlem Nisbet H, Nisbet C, Akar A, Cevik M, Onder Karayigit M. Effects of exposure to electromagnetic field $(1.8 / 0.9 \mathrm{GHz})$ on testicular function and structure in growing rats. Res Vet Sci. 2012;93: 1001-1005. doi:10.1016/j.rvsc.2011.10.023

53. Cetkin M, Kızılkan N, Demirel C, Bozdağ Z, Erkılıç S, Erbağcı H. Quantitative changes in testicular structure and function in rat exposed to mobile phone radiation. Andrologia. 2017; 49: e12761. doi:10.1111/ and.12761

54. World Health Organization. WHO laboratory manual for the examination and processing of human semen. 5th ed. Geneva: World Health Organization; 2010.

55. Wosiński S. The influence of the composition and manufacturing conditions of ceramic and polymer composites on the ability of shielding an alternating electric field. Poznan University of Technology. 2010.

56. Wosiński S. Solution for impregnation of materials shielding lowfrequency electric field and the shielding material. WO/2010/093270, 2010.

57. Ashley JR. The safety of overhead power lines. IEEE Eng Med Biol Mag. 1997; 16: 25-6, 28.

58. King RW. An examination of underlying physical principles. The interaction of power-line electromagnetic fields with the human body. IEEE Eng Med Biol Mag. 1998; 17: 67-73; discussion 73-8.

59. Mailankot M, Kunnath AP, Jayalekshmi H, Koduru B, Valsalan R. Radio frequency electromagnetic radiation (RF-EMR) from GSM $(0.9 / 1.8 \mathrm{GHz})$ mobile phones induces oxidative stress and reduces sperm motility in rats. Clinics (Sao Paulo). 2009; 64: 561-5. doi:10.1590/s180759322009000600011

60. Gye MC, Park CJ. Effect of electromagnetic field exposure on the reproductive system. Clin Exp Reprod Med. 2012; 39: 1. doi:10.5653/ cerm.2012.39.1.1

61. Ghanbari M, Mortazavi SB, Khavanin A, Khazaei M. The Effects of Cell Phone Waves (900 MHz-GSM Band) on Sperm Parameters and Total Antioxidant Capacity in Rats. Int J Fertil Steril. 2013; 7: 21-8.

62. Gorpinchenko I, Nikitin O, Banyra O, Shulyak A. The influence of direct mobile phone radiation on sperm quality. Cent Eur J Urol. 2014; 67: 65-71. doi:10.5173/ceju.2014.01.art14
63. Bernabò N, Tettamanti E, Pistilli MG, Nardinocchi D, Berardinelli $\mathrm{P}$, Mattioli $\mathrm{M}$, et al. Effects of $50 \mathrm{~Hz}$ extremely low frequency magnetic field on the morphology and function of boar spermatozoa capacitated in vitro. Theriogenology. 2007; 67: 801-815. doi:10.1016/j. theriogenology.2006.10.014

64. Iorio R, Scrimaglio R, Rantucci E, Monache SD, Di Gaetano A, Finetti $\mathrm{N}$, et al. A preliminary study of oscillating electromagnetic field effects on human spermatozoon motility. Bioelectromagnetics. 2007; 28: 72-75. doi:10.1002/bem. 20278

65. Iorio R, Delle Monache S, Bennato F, Di Bartolomeo C, Scrimaglio R, Cinque $\mathrm{B}$, et al. Involvement of mitochondrial activity in mediating ELFEMF stimulatory effect on human sperm motility. Bioelectromagnetics. 2011; 32: 15-27. doi:10.1002/bem.20602

66. Hong R, Zhang Y, Liu Y, Weng E. Effects of extremely low frequency electromagnetic fields on DNA of testicular cells and sperm chromatin structure in mice. Chinese J Ind Hyg Occup Dis. 2005; 23: 414-7.

67. Al-Akhras M-A, Darmani H, Elbetieha A. Influence of $50 \mathrm{~Hz}$ magnetic field on sex hormones and other fertility parameters of adult male rats. Bioelectromagnetics. 2006; 27: 127-131. doi:10.1002/bem.20186

68. Sun Y-L, Zhou W-J, Wu J-Q, Gao E-S. Does exposure to computers affect the routine parameters of semen quality? Asian J Androl. 2005; 7: 263-266. doi:10.1111/j.1745-7262.2005.00045.x

69. Wdowiak A, Wdowiak L, Wiktor H. Evaluation of the effect of using mobile phones on male fertility. Ann Agric Environ Med. 2007; 14: 169-72.

70. Gutschi T, Mohamad Al-Ali B, Shamloul R, Pummer K, Trummer H. Impact of cell phone use on men's semen parameters. Andrologia. 2011; 43: 312-316. doi:10.1111/j.1439-0272.2011.01075.x

71. Falzone N, Huyser C, Becker P, Leszczynski D, Franken DR. The effect of pulsed 900-MHz GSM mobile phone radiation on the acrosome reaction, head morphometry and zona binding of human spermatozoa. Int J Androl. 2011; 34: 20-26. doi:10.1111/j.1365-2605.2010.01054.x

72. Otitoloju AA, Obe IA, Adewale OA, Otubanjo OA, Osunkalu VO. Preliminary Study on the Induction of Sperm Head Abnormalities in Mice, Mus musculus, Exposed to Radiofrequency Radiations from Global System for Mobile Communication Base Stations. Bull Environ Contam Toxicol. 2010; 84: 51-54. doi:10.1007/s00128-009-9894-2

73. Gul A, Çelebi H, Uğraş S. The effects of microwave emitted by cellular phones on ovarian follicles in rats. Arch Gynecol Obstet. 2009; 280: 729-733. doi:10.1007/s00404-009-0972-9

74. Aitken RJ, Bennetts LE, Sawyer D, Wiklendt AM, King BV. Impact of radio frequency electromagnetic radiation on DNA integrity in the male germline. Int J Androl. 2005; 28: 171-179. doi:10.1111/j.13652605.2005.00531.x

75. Kumar S, Kesari KK, Behari J. The therapeutic effect of a pulsed electromagnetic field on the reproductive patterns of male Wistar rats exposed to a 2.45-GHz microwave field. Clinics (Sao Paulo). 2011; 66: 1237-45. doi:10.1590/s1807-59322011000700020

76. Atasoy HI, Gunal MY, Atasoy P, Elgun S, Bugdayci G. Immunohistopathologic demonstration of deleterious effects on growing rat testes of radiofrequency waves emitted from conventional Wi-Fi devices. J Pediatr Urol. 2013; 9: 223-229. doi:10.1016/j.jpurol.2012.02.015

77. Poulletier de Gannes F, Billaudel B, Haro E, Taxile M, Le Montagner L, Hurtier A, et al. Rat fertility and embryo fetal development: Influence of exposure to the Wi-Fi signal. Reprod Toxicol. 2013; 36: 1-5. doi:10.1016/j.reprotox.2012.11.003 